\title{
Maternal Gestational Diabetes Associated with Higher Child BMI Z- Score at Preschool and Lower Likelihood of Breastfeeding Initiation
}

\author{
Rana H. Mosli ${ }^{1, *}$, Manal N. Al-Lahyani ${ }^{1}$, Amani Najjar ${ }^{1}$, Doaa A. Zoghbi ${ }^{1}$, \\ Rawan H. Al-Haddad ${ }^{1}$ and Hala H. Mosli ${ }^{2}$ \\ ${ }^{1}$ Clinical Nutrition Department, Faculty of Applied Medical Sciences, King Abdulaziz University, P.O. Box \\ 80215, Jeddah 21589, KSA; ${ }^{2}$ Division of Endocrinology and Metabolism, Department of Medicine, Faculty of \\ Medicine, King Abdulaziz University, P.O.Box 80215, Jeddah 21589, KSA
}

\begin{abstract}
Objectives: To examine the association of maternal GDM with 1) child BMI z-score at preschool; 2) breastfeeding initiation and duration, while adjusting for child birthweight in addition to potential confounders.

Method: Sample included 53 children ( 3 - 5 years old) recruited from two preschools in Jeddah, Saudi Arabia. Mothers completed a self-administered questionnaire. Child anthropometry was completed using standardized procedures. BMI z-scores were calculated using the WHO standards/reference data. Linear regression models were tested to examine the association between maternal GDM and child BMI z-score, as well as breastfeeding duration. Logistic regression models were tested to examine the association between maternal GDM and breastfeeding initiation. Models were adjusted for child birthweight, maternal BMI, and maternal age at pregnancy.

Results: Mean child BMI z-score was $1.10(\mathrm{SD}=1.22)$. About one quarter $(24.5 \%)$ of mothers reported being diagnosed with GDM. Mean birthweight of children whose mothers were diagnosed with GDM was $3.10 \mathrm{~kg}(\mathrm{SD}=0.74)$. Adjusting for covariates, we found that maternal GDM was associated with increased child $\mathrm{BMI} z$-score $(B=1.04,95 \% \mathrm{Cl}=0.14$ 1.94, $\mathrm{P}$-value $=0.02)$, and lower odds of breastfeeding initiation $(\mathrm{OR}=0.10,95 \% \mathrm{Cl}=0.02-0.49, \mathrm{P}$-value $=0.005)$. Maternal GDM was not associated with breastfeeding duration $(B=-4.75,95 \% \mathrm{Cl}:-11.79-2.29, \mathrm{P}-\mathrm{value}=0.18)$.

Conclusion: Findings suggest that maternal GDM is associated with higher child BMI z-score at preschool and lower likelihood of breastfeeding initiation. Studies are needed in order to identify the underlying mechanisms of associations. Obesity prevention programs may target children whose mothers were diagnosed with GDM; prenatal breastfeeding counseling may be offered.
\end{abstract}

Keywords: Gestational diabetes, Breastfeeding, BMI z-score, Preschool.

\section{BACKGROUND}

Weight status during the first few years of life is a strong determinant of life-long obesity risk and morbidity [1]. Obesity during childhood is associated with premature onset of health complications; Obese children are more likely to suffer from hypertension, prediabetes, and dyslipidemia [2-5]. Despite global efforts to combat childhood obesity, rates remain high $[6,7]$. Childhood obesity prevalence continues to increase in both developed and developing countries $[6,7]$, and worldwide prevalence of overweight and obesity among preschoolers is expected to reach $9.1 \%$ by the year 2020 [6]. In the Kingdom of Saudi Arabia (KSA), the prevalence of overweight and obesity among children is concerning, where around $14.5 \%$ of 1-6 year olds [8] and $32 \%$ of $5-18$ year olds [9] were found to be overweight or obese.

In order to design and effectively target obesity prevention and intervention efforts, risk factors for

*Address correspondence to this author at the Clinical Nutrition Department, Faculty of Applied Medical Sciences, King Abdulaziz University, P.O. Box 80215, Jeddah 21589, KSA; Tel: +(966)126400000 ext: 24216;

Fax: +(966)126761272; E-mail: aimuwseli@kau.edu.sa childhood obesity must first be identified and understood. Maternal-related risk factors may be essential focal points for family-centered programs aiming for early obesity prevention. Maternal-related risk factors include those relating to fetal intrauterine exposures that consequently lead to metabolic changes in the fetus, increasing later on obesity risk. Maternal obesity and gestational diabetes mellitus (GDM) are two factors that may alter normal fetal growth and programming, and may potentially affect subsequent infant growth and metabolism [10].

The association between maternal and child obesity is well-established [11, 12]. However, there is conflicting evidence regarding the association between maternal GDM and child body mass index (BMI) [1316]. While some prospective studies found that maternal GDM is associated with child obesity $[15,17]$, other longitudinal and retrospective studies found that this association is entirely explained by maternal BMI or child birthweight $[10,13,18-20]$; Some studies showed that the association between maternal GDM and child obesity only existed among children who were large-for-gestational age [10, 20, 21], and children 
whose mothers were overweight during pregnancy [22]. Other findings showed no association between GDM and child BMI in various age groups [11, 14-16, 23], including 2- to 4-year-old children [13, 16, 24].

Furthermore, ample evidence from studies conducted in Western and Arab countries suggest that overweight and obese mothers may have poor breastfeeding outcomes $[25,26]$, possibly due to delayed onset of lactogenesis, or having difficulty with physically positioning the newborn correctly $[25,26]$. However, there is insufficient evidence regarding the association between GDM and breastfeeding outcomes, regardless of maternal BMI and child birthweight; It is unclear whether mothers with GDM, but with normal weight neonates, are less likely to initiate breastfeeding and breastfeed for a longer duration. Finally, the association of maternal GDM with child BMI z-score and breastfeeding initiation and duration have not been previously explored in a Saudi sample. Given the increasing obesity rates and high prevalence of pregnancy diabetes (about 19\% of pregnancies) [27] in countries undergoing a nutrition transition, such as KSA [28-31], it is important to explore associations between maternal GDM, child BMI z-score, and breastfeeding outcomes, in a comparative sample.

Understanding these associations can help effective targeting and design of obesity prevention programs that are sensitive to characteristics of a population undergoing a nutrition transition. The objective of this study was to examine the association between GDM and child BMI at preschool, as well as the association between GDM and breastfeeding initiation and duration, while adjusting for child birthweight in addition to potential confounders.

\section{MATERIALS AND METHODS}

\section{Sample and Procedure}

Participants were recruited through an opt-in approach from two preschools in Jeddah, Saudi Arabia. Study packets were sent home in the backpacks of 249 kindergarten students. Each study packet included a recruitment form to screen for eligibility, a consent form, and the study questionnaire. All forms were in Arabic language, the native language of the participants. Of the 249 study packets sent home, 65 (26\%) were completed by mothers and returned to the school in a sealed envelope. Of the 65 participants, 53 had complete data on all variables, and these 53 mothers and their children were included in the final sample. The study inclusion criteria include; child age between 3 and 5 years old, with no serious medical problems or history of food allergies and living with his/her biological mother, mother fluent in Arabic and does not suffer from chronic illnesses, including type 1 and 2 diabetes mellitus. Participants received a small monetary incentive upon completion of the study. Ethical approval for this study was obtained from King Abdul-Aziz University Biomedical Ethics Unit (registration number HA-02-J-008).

\section{Measures}

The study questionnaire comprised of questions regarding the index child, such as the child's sex and birthweight, and questions regarding maternal characteristics, including the mother's weight and height (used to calculate BMI as weight $(\mathrm{kg}$ ) divided by height $\left.^{2}\left(\mathrm{~m}^{2}\right)\right)$, age at the time of the pregnancy, and whether or not she was ever diagnosed with gestational diabetes while pregnant with the index child. Questions regarding breastfeeding experience with the index child include questions about whether or not breastfeeding was ever initiated (used in the analysis as a categorical variable) and duration of breastfeeding. (used in the analysis as a continuous variable). To assess face validity, we performed a pretest of the questionnaire with a group of mothers with similar characteristics as mothers in our study sample. This helped us ensure clarity of the questions and response options. Furthermore, the questions were reviewed by an expert in the field to further establish validity.

\section{Primary Outcome: Child BMI z-Score}

Anthropometric measurements were taken from children at the preschools following standardized procedures. A digital scale and stadiometer were used. To avoid transcription error, two trained clinical dietitians were present to measure weight and height; One ensured correct positioning of the child and read the measurement aloud, and the second recorded the data. Shoes and heavy clothing were removed. The child was asked to stand still on the scale, with his/her weight equally distributed on both feet. Each child was weighed twice, and if the two readings were inconsistent by more than $0.1 \mathrm{~kg}$, the child was weighed two more times. Similarly, height was measured twice; If the measurements varied by more than $0.5 \mathrm{~cm}$, two more measurements were taken [32]. BMI z-scores were calculated based on the age- and sex-specific World Health Organization (WHO) growth 
standards for children $\leq 5$ years old and the WHO growth reference data for children who were between 5 and 6 years old $[33,34]$.

\section{Secondary Outcomes}

Secondary outcomes in this study include a dichotomous variable for breastfeeding initiation (yes vs. no), and a continuous variable for breastfeeding duration (in months).

\section{Primary Predictor}

The primary predictor in this study is a dichotomous variable for a GDM diagnosis during pregnancy (yes vs. no).

\section{Covariates}

Child birthweight and maternal BMI and age at pregnancy (all included as continuous variables) were identified a priori from the literature for adjustment in statistical analyses. It is well documented in the literature that infants born to mothers with pregnancy diabetes are more likely to be macrosomic and have high birthweights $[18,35,36]$, primarily due to intrauterine exposure to hyperglycemia. High birthweight may lead to increased child BMI and obesity risk [37]. Similarly, maternal BMI and age at pregnancy were both found to be associated with maternal GDM and child obesity risk [36]. Child birthweight and maternal BMI and age at pregnancy were also found to be associated with breastfeeding initiation and duration [26, 38].

\section{Statistical Analysis}

Analyses were conducted using IBM SPSS Statistics 21.0 (Armonk, NY, USA). Descriptive statistics were used to examine sample characteristics. To examine differences in maternal and child characteristics by maternal GDM, Chi-square statistics was used for categorical variables, and independent samples t-tests were used for continuous variables.

Linear regression models were tested to examine the association of maternal GDM with child BMI z-score and breastfeeding duration. Logistic regression models were tested to examine the association between maternal GDM and breastfeeding initiation. We first ran unadjusted models, then, models were adjusted for child birthweight, maternal BMI and maternal age at pregnancy. Significance level was set at P-value $\leq$ 0.05 .

\section{RESULTS}

Mean child BMI z-score was $1.10(\mathrm{SD}=1.22)$. About half $(47.2 \%)$ of the children in the study sample was male. About one quarter $(24.5 \%)$ of mothers reported being diagnosed with GDM while pregnant with the index child, and about $70 \%$ reported that they had initiated breastfeeding after birth. Mean breastfeeding duration in the study sample was 14.8 months $(\mathrm{SD}=$ 8.62). Mean birthweight of children whose mothers were diagnosed with GDM was $3.10 \mathrm{~kg}(\mathrm{SD}=0.74)$; There was no significant difference in child birthweight between mothers who reported a GDM diagnosis and those who did not (P-value $>0.05)$. However, there was a significant difference in child BMI z-score and prevalence of breastfeeding initiation between the two groups (P-values <0.05) (Table 1$)$.

Tables 2, 3, and 4 show the adjusted and unadjusted associations of maternal GDM with child BMI z-score, breastfeeding initiation and breastfeeding

Table 1: Sample Characteristics and Differences by Maternal Gestational Diabetes (GDM)

\begin{tabular}{|c|c|c|c|c|}
\hline Variable & $\begin{array}{l}\text { Total } \\
\mathrm{N}=53\end{array}$ & $\begin{array}{l}\text { Diagnosis of } \\
\text { GDM reported } \\
\qquad(n=13)\end{array}$ & $\begin{array}{l}\text { Diagnosis of GDM } \\
\text { not reported } \\
\qquad(n=40)\end{array}$ & P-value \\
\hline Child BMI z-score & $1.10(1.22)$ & $1.74(1.60)$ & $0.88(1.00)$ & 0.03 \\
\hline Maternal BMI & $26.8(6.96)$ & $26.0(5.61)$ & $27.0(7.38)$ & 0.68 \\
\hline $\begin{array}{c}\text { Breastfeeding Initiated, n (\%) } \\
\text { Yes } \\
\text { No }\end{array}$ & $37(69.8)$ & $\begin{array}{l}5(38.5) \\
8(61.5)\end{array}$ & $\begin{array}{c}32(80.0) \\
8(20.0)\end{array}$ & 0.005 \\
\hline Breastfeeding Duration (in months), M (SD) & $14.8(8.62)$ & $11.1(9.34)$ & $15.7(8.30)$ & 0.15 \\
\hline
\end{tabular}

Table showing means (M) and standard deviations (SD) or counts $(n)$ and percentages $(\%)$.

Significant differences between maternal GDM groups tested by $t$-tests for continuous variables and Chi-square tests for categorical variables. 
Table 2: Associations of Maternal Gestational Diabetes (GDM) with Child BMI Z-Score

\begin{tabular}{|c|c|c|}
\hline & $\begin{array}{l}\text { Unadjusted Beta Coefficient }(95 \% \mathrm{Cl}) \\
\qquad(\mathrm{n}=53)\end{array}$ & $\begin{array}{c}\text { Beta Coefficient }(95 \% \mathrm{Cl})(\mathrm{n}=53) \text { Adjusted for } \\
\text { Covariates }\end{array}$ \\
\hline $\begin{array}{c}\text { Diagnosis of Maternal GDM Reported } \\
\text { Yes } \\
\text { No }\end{array}$ & $\begin{array}{c}0.86(0.07-1.64)^{*} \\
1\end{array}$ & $\begin{array}{c}1.04(0.14-1.94)^{*} \\
1\end{array}$ \\
\hline
\end{tabular}

${ }^{*}$ P-value $<0.05$

Linear regression model adjusted for child birthweight, maternal BMI, and maternal age at pregnancy.

Table 3: Associations of Maternal Gestational Diabetes (GDM) with Breastfeeding Initiation

\begin{tabular}{|c|c|c|}
\hline & Unadjusted Odds Ratio (95\% Cl) \\
$(\mathbf{n = 5 3 )}$ & $\begin{array}{c}\text { Odds Ratio (95\% Cl) (n=53) Adjusted for } \\
\text { Covariates }\end{array}$ \\
\hline \hline Diagnosis of Maternal GDM Reported & & $0.10(0.02-0.49)$ \\
Yes & $0.16(0.04-0.61)^{* *}$ \\
No & 1 & 1 \\
\hline
\end{tabular}

${ }^{* *}$ P-value $<0.01$

Logistic regression model adjusted for child birthweight, maternal BMI, and maternal age at pregnancy.

Table 4: Associations of Maternal Gestational Diabetes (GDM) with Breastfeeding Duration

\begin{tabular}{|c|c|c|}
\hline & $\begin{array}{l}\text { Unadjusted Beta Coefficient }(95 \% \mathrm{Cl}) \\
\qquad(\mathrm{n}=53)\end{array}$ & $\begin{array}{l}\text { Beta Coefficient }(95 \% \mathrm{Cl})(\mathrm{n}=53) \\
\text { Adjusted for Covariates }\end{array}$ \\
\hline $\begin{array}{l}\text { Diagnosis of Maternal GDM Reported } \\
\text { Yes } \\
\text { No }\end{array}$ & $\begin{array}{c}-4.45(-11.00-1.83) \\
1\end{array}$ & $\begin{array}{c}-4.75(-11.79-2.29) \\
1\end{array}$ \\
\hline
\end{tabular}

Linear regression model adjusted for child birthweight, maternal BMI, and maternal age at pregnancy.

duration. Adjusting for child birthweight, maternal age at pregnancy and current maternal BMI, we found that maternal GDM was associated with increased child BMI $z$-score at preschool $(B=1.04,95 \%$ confidence interval $(\mathrm{Cl})=0.14-1.94, \mathrm{P}$-value $=0.02)$. Maternal GDM was associated with lower odds of breastfeeding initiation $(\mathrm{OR}=0.10,95 \% \mathrm{Cl}=0.02-0.49$, P-value $=$ 0.005). Furthermore, GDM was negatively associated with breastfeeding duration. However, this association did not reach statistical significance $(B=-4.75,95 \% \mathrm{Cl}$ : $-11.79-2.29$, P-value $=0.18$ )

\section{DISCUSSION}

Findings from our study suggest that a positive GDM diagnosis in mothers is associated with higher child BMI z-score at preschool. A positive GDM diagnosis in mothers was also associated with lower likelihood that mothers would initiate breastfeeding after birth. Results were not attenuated by adjusting for child birthweight, maternal BMI, and maternal age at pregnancy. Furthermore, mean birthweight of children whose mothers were diagnosed with GDM was similar to mean birthweight of children whose mothers were not diagnosed with GDM. This suggests that there may be other mechanisms, possibly involving the intrauterine environment and fetal exposures, that lead to increased child adiposity during early years. In addition, there may be other associated factors that explain the poor breastfeeding outcomes in mothers diagnosed with GDM.

Offspring of diabetic mothers are susceptible to fetal programming in the intrauterine metabolic environment via insulin resistance and hypothalamic changes [17, 39]; Hyperlipidemia often present in GDM may negatively affect leptin sensitivity in the developing fetal tissues, particularly in the hypothalamus [40]. The hypothalamus is responsible for secreting several neuropeptides and hormones which play a key role in appetite and metabolism regulation. Neuropeptide $Y$ (NPY), secreted by neurons expressed in the arcuate nucleus in the hypothalamus stimulates food intake, causes a reduction in energy expenditure and, through peripheral receptors, leads to weight gain. Agouti related peptide (AGRP), also secreted by neurons of 
the arcuate nucleus, causes increased energy intake and weight gain. These peptides decrease energy intake by reducing the appetite and have a net negative effect on weight [41, 42]. Since the 1950's, Pederson hypothesized the following "maternal hyperglycaemia results in foetal hyperglycaemia and, hence, in hypertrophy of foetal islet tissue with insulinhypersecretion. This again means a greater foetal utilization of glucose. This phenomenon will explain several abnormal structure and changes found in the newborn". Since then, many studies have been published that substantiate this theory and in fact, mechanisms to explain it have been explored in animals and in humans [43-45]. Our findings further support Pederson's hypothesis, and future work is needed in order to identify the exact underlying pathways.

Our findings are consistent with previous studies that reported an association between intrauterine exposure to GDM and obesity in other age groups, including school-age [15, 17], and adolescence [46]. Although some found that the association between GDM and child obesity was entirely explained by child birthweight or maternal BMI [10, 13, 18-20], and others found no association between GDM and child BMI [11, $14,16,23]$, this discrepancy could be due to differences in characteristics of the populations studied, such as age of enrolled children and weight status outcome used. In addition, the prevalence of GDM in our sample was high at $24.5 \%$, while previous studies that found null associations had lower prevalence in their samples (e.g., $4 \%$ and $11 \%$ ) [14, 23].

Furthermore, our study supports other findings that showed poor breastfeeding outcomes for mothers with gestational diabetes $[47,48]$, although our study was the first, to our knowledge, to adjust for child birthweight, maternal BMI, and maternal age at pregnancy [48]. Our results suggest that factors other than those relating to correctly positioning the infant might come into play; Mothers with gestational diabetes may worry more about the infant's health, experience low milk supply, or delayed lactogenesis [47, 49], which may adversely affect breastfeeding initiation. Our study did not find a significant association between maternal GDM and breastfeeding duration. This could be due to the majority of mothers reporting a GDM diagnosis also reporting that they've never initiated breastfeeding.

This study has several strengths. To our knowledge, this is the first study to investigate the association of maternal GDM with child BMI z-score and breastfeeding initiation and duration in a Saudi sample, while adjusting for child birthweight, maternal BMI and maternal age at pregnancy. Our study was also the first to include 3- to 5-year-old children. Weight and height of children was objectively measured, and face validity of the questionnaire was established. This study also has some limitations. First, the sample size was small, which might have affected our ability to detect significant associations, and adjust for potential confounders, such as maternal educational level and smoking status. Mothers were categorized as having a history of GDM only if they were aware of and had reported a GDM diagnosis while pregnant with the index child; Maternal GDM was not objectively measured, and different blood glucose levels were not examined. However, we would expect such approach to result in a higher prevalence of GDM in our sample, and consequently, stronger associations. Furthermore, child birthweight was obtained through maternal report and not through hospital records, although both were found to be significantly comparable [50].

Our findings suggest that maternal GDM is associated with higher BMI z-score at preschool, and that this association may not be driven by higher birthweight. Mothers with GDM were also less likely to initiate breastfeeding. Studies are needed in order to identify the underlying mechanisms of associations. Obesity prevention and intervention programs may target children whose mothers were diagnosed with GDM prior to preschool years, and counseling may be offered prenatally to increase breastfeeding initiation.

\section{AUTHORSHIP CONTRIBUTIONS}

$\mathrm{RM}, \mathrm{MA}, \mathrm{AN}, \mathrm{DZ}$, and $\mathrm{RH}$ designed the study and coordinated and supervised data collection. RM analyzed the data, and drafted the initial manuscript. HM provided input on the analysis plan and critically reviewed the manuscript. All authors have approved the final manuscript as submitted.

\section{FINANCIAL DISCLOSURE}

The authors have no financial relationships relevant to this article to disclose.

\section{CONFLICT OF INTEREST}

The authors have no conflicts of interest to disclose.

\section{REFERENCES}

[1] Cunningham SA, Kramer MR, Narayan KMV. Incidence of childhood obesity in the United States N Engl J Med 2014; 370(5): 403-11. 
[2] Li C, Ford ES, Zhao G, Mokdad AH. Prevalence of prediabetes and its association with clustering of cardiometabolic risk factors and hyperinsulinemia among U.S. adolescents: National Health and Nutrition Examination Survey 2005-2006. Diabetes Care 2009; 32(2): 342-7. https://doi.org/10.2337/dc08-1128

[3] Deckelbaum RJ, Williams CL. Childhood obesity: The health issue. Obes Res 2001; 9(S11): 239S-43S. https://doi.org/10.1038/oby.2001.125

[4] Freedman DS, Mei Z, Srinivasan SR, Berenson GS, Dietz $\mathrm{WH}$. Cardiovascular risk factors and excess adiposity among overweight children and adolescents: the Bogalusa Heart Study. J Pediatr 2007; 150(1): 12-7 e2.

[5] Daniels SR, Arnett DK, Eckel RH, Gidding SS, Hayman LL, Kumanyika $S$, et al. Overweight in children and adolescents: pathophysiology, consequences, prevention, and treatment. Circulation 2005; 111(15): 1999-2012. https://doi.org/10.1161/01.CIR.0000161369.71722.10

[6] De-Onis M, Blössner M, Borghi E. Global prevalence and trends of overweight and obesity among preschool children. The American Journal of Clinical Nutrition 2010; 92(5): 125764. https://doi.org/10.3945/ajen.2010.29786

[7] Wang Y, Lobstein TI. Worldwide trends in childhood overweight and obesity. Pediatric Obesity 2006; 1(1): 11-25. https://doi.org/10.1080/17477160600586747

[8] El-Hazmi MA, Warsy AS. The prevalence of obesity and overweight in 1-18-year-old Saudi children. Annals of Saudi Medicine 2002; 22(5/6): 303-7. https://doi.org/10.5144/0256-4947.2002.303

[9] El-Mouzan M, Foster P, Al-Herbish A, Al-Salloum A, A AlOmer A, Qurachi $M$, et al. Prevalence of overweight and obesity in Saudi children and adolescents. Annals of Saudi medicine 2010; 30(3): p.203.

[10] Boney CM, A Verma, Tucker R, Vohr BR. Metabolic syndrome in childhood: Association with birth weight, maternal obesity, and gestational diabetes mellitus. Pediatrics 2005; 115(3): e290-e6.

[11] atalano PM, Farrell K, Thomas A, Huston-Presley L, Mencin $\mathrm{P}$, Mouzon SHD, et al. Perinatal risk factors for childhood obesity and metabolic dysregulation. The American Journal of Clinical Nutrition 2009: ajcn-27416.

[12] Hesketh k, Crawford D, Salmon J, Jackson M, Campbell K. Associations between family circumstance and weight status of Australian children. Journal of Pediatric Obesity 2007; 2(2): 86-96. https://doi.org/10.1080/17477160601148554

[13] Kim SY, England JL, Sharma JA, Njoroge T. Gestational diabetes mellitus and risk of childhood overweight and obesity in offspring: A systematic review. Experimental Diabetes Research 2011; 2011.

[14] Wright CS, Rifas-Shiman SL, Rich-Edwards JW, Taveras EM, Gillman MW, E EO. Intrauterine exposure to gestational diabetes, child adiposity, and blood pressure. American Journal of Hypertension 2008; 22(2): 215-20.

https://doi.org/10.1038/ajh.2008.326

[15] Hillier TA, Pedula KL, Schmidt MM, Mullen JA, Charles MA, DJ DJP. Childhood obesity and metabolic imprinting. Diabetes Care 2007; 30(9): 2287-92. https://doi.org/10.2337/dc06-2361

[16] Pettitt DJ, McKenna S, McLaughlin C, Patterson CC, Hadden DR, McCancE DR. Maternal glucose at 28 weeks of gestation is not associated with obesity in 2-year-old offspring. Diabetes Care 2010; 33(6): 1219-23 https://doi.org/10.2337/dc09-2384

[17] Zhu Y, Olsen SF, Mendola P, Yeung EH, Vaag A, Bowers K, et al. Growth and obesity through the first $7 \mathrm{y}$ of life in association with levels of maternal glycemia during pregnancy: a prospective cohort study. The American Journal of Clinical Nutrition 2016; 103(3). https://doi.org/10.3945/ajcn.115.121780

[18] Gillman MW, Rifas-Shiman S, Berkey CS, Field AE, Colditz GA. Maternal gestational diabetes, birth weight, and adolescent obesity. Pediatrics 2003; 111(3): e221-6. https://doi.org/10.1542/peds.111.3.e221

[19] Kim SY, Sharma AJ, Callaghan WM. Gestational diabetes and childhood obesity: What is the link? Current Opinion in Obstetrics \& Gynecology 2012; 24(6): 376.

https://doi.org/10.1097/GCO.0b013e328359f0f4

[20] Vohr BR, McGarvey ST. Growth patterns of large-forgestational-age and appropriate-for-gestational-age infants of gestational diabetic mothers and control mothers at age 1 year. Diabetes Care 1997; 20(7): 1066-72. https://doi.org/10.2337/diacare.20.7.1066

[21] Vohr BR, McGarvey ST, Tucker R. Effects of maternal gestational diabetes on offspring adiposity at 4-7 years of age. Diabetes Care 1999; 22(8): 1284-91. https://doi.org/10.2337/diacare.22.8.1284

[22] Pirkola J, Pouta A, Bloigu A, Hartikainen AL, Laitinen J, Järvelin MR, et al. Risks of overweight and abdominal obesity at age 16 years associated with prenatal exposures to maternal prepregnancy overweight and gestational diabetes mellitus. Diabetes Care 2010; 33(5): 1115-21. https://doi.org/10.2337/dc09-1871

[23] Whitaker RC, Pepe MS, Seidel KD, Wright JA, Knopp RH. Gestational diabetes and the risk of offspring obesity. Pediatrics 1998; 101(2): e9. https://doi.org/10.1542/peds.101.2.e9

[24] Pham MT, Brubaker K, Pruett K, Caughey AB. Risk of childhood obesity in the toddler offspring of mothers with gestational diabetes. Obstetrics \& Gynecology 2013; 121(5): 976-82. https://doi.org/10.1097/AOG.0b013e31828bf70d

[25] Rasmussen KM, Kjolhede CL. Prepregnant overweight and obesity diminish the prolactin response to suckling in the first week postpartum. Pediatrics 2004; 113(5): e465-e71.

https://doi.org/10.1542/peds.113.5.e465

[26] Amir LH, Donath S. A systematic review of maternal obesity and breastfeeding intention, initiation and duration. BMC Pregnancy and Childbirth 2007; 7(1): 9. https://doi.org/10.1186/1471-2393-7-9

[27] Wahabi HA, Esmaeil SA, Fayed A, Alzeidan RA. Gestational diabetes mellitus: maternal and perinatal outcomes in King Khalid University Hospital, Saudi Arabia. he Journal of the Egyptian Public Health Association 2013; 88(2): 104-8. https://doi.org/10.1097/01.EPX.0000430392.57811.20

[28] Sibai SAM, Nasreddine L, Mokdad AH, Adra N, Tabet M, Hwalla N. Nutrition transition and cardiovascular disease risk factors in Middle East and North Africa countries: reviewing the evidence. Annals of Nutrition and Metabolism 2010; 57(34): 193-203. https://doi.org/10.1159/000321527

[29] Ng SW, Zaghloul S, Ali H, Harrison G, Yeatts K, El-Sadig M, et al. Nutrition transition in the United Arab Emirates. European Journal of Clinical Nutrition 2011; 65(12): 3281337. https://doi.org/10.1038/ejcn.2011.135

[30] Al-Othaimeen Al, M Al-Nozha M, Osman AK. Obesity: an emerging problem in Saudi Arabia. Analysis of data from the National Nutrition Survey. Eastern Mediterranean Health Journal 2007; 13(2): 441-8.

[31] Elhadd TA, Al-Amoudi AA, Alzahrani AS. Epidemiology, clinical and complications profile of diabetes in Saudi Arabia: A review. Annals of Saudi Medicine 2007; 27(4): 241. https://doi.org/10.4103/0256-4947.51484

[32] Mosli RH, Miller AL, Peterson KE, Kaciroti N, Rosenblum K, Baylin A, et al. Birth order and sibship composition as 
predictors of overweight or obesity among low-income 4- to 8-year-old children. Pediatric obesity 2016; 11(1): 40-6. https://doi.org/10.1111/ijpo.12018

[33] Onis MD, Onyango AW, Borghi E, Siyam A, Nishida C, Siekmann J. Development of a WHO growth reference for school-aged children and adolescents. Bulletin of the World health Organization 2007; 85(9): 660-7. https://doi.org/10.2471/BLT.07.043497

[34] World Health Organization. WHO child growth standards: length/height for age, weight-for-age, weight-for-length, weight-for-height and body mass index-for-age, methods and development. World Health Organization; 2006.

[35] Persson B, Hanson U. Neonatal morbidities in gestational diabetes mellitus. Diabetes Care 1998; 1(21): B79.

[36] Xiong $X$, Saunders LD, Wang FL, Demianczuk NN. Gestational diabetes mellitus: Prevalence, risk factors, maternal and infant outcomes. International Journal of Gynecology \& Obstetrics 2001; 75(3): 221-8. https://doi.org/10.1016/S0020-7292(01)00496-9

[37] Cnattingius S, Villamor E, Lagerros YT, Wikström AK, Granath F. High birth weight and obesity--a vicious circle across generations. International Journal of Obesity 2012; 36(10): 1320.

https://doi.org/10.1038/ijo.2011.248

[38] Donath SM, Amir LH. Does maternal obesity adversely affect breastfeeding initiation and duration? Journal of Paediatrics and Child Health 2000; 36(5): 482-6. https://doi.org/10.1046/j.1440-1754.2000.00562.x

[39] Ornoy A. Prenatal origin of obesity and their complications: Gestational diabetes, maternal overweight and the paradoxical effects of fetal growth restriction and macrosomia. Reproductive Toxicology 2011; 32(2): 205-12. https://doi.org/10.1016/j.reprotox.2011.05.002

[40] RS Ahima R, Antwi DA. Brain Regulation of Appetite and Satiety. Endocrinology and Metabolism Clinics of North America 2008; 37(4): 811-23. https://doi.org/10.1016/j.ecl.2008.08.005

[41] Pedersen J. Diabetes and pregnancy: Blood sugar of newborn infants. Danish Science Press; Copenhagen1952.
[42] Pedersen J. The pregnant diabetic and her newborn: Problems and management. Baltimore, MD: William \& Wilkins; 1967. p. 128-37.

[43] Ogata ES, Collins Jr JW, Finley S. Insulin injection in the fetal rat: accelerated intrauterine growth and altered fetal and neonatal glucose homeostasis. Metabolism 1988; 37(7): 64955 .

https://doi.org/10.1016/0026-0495(88)90084-4

[44] Susa JB, Neave C, Sehgal P, Singer DB, Zeller WP Schwartz R. Effects of physiologic hyperinsulinemia on fetal growth and composition. Diabetes 1984; 33: 656-60. https://doi.org/10.2337/diab.33.7.656

[45] Philipps AF, Rosenkrantz TS, RM RMC, Knox I, Chaffin DG, Raye RJ. Effects of fetal insulin deficiency on growth in fetal lambs. Diabetes 1991; 40(1): 20-7. https://doi.org/10.2337/diab.40.1.20

[46] Vääräsmäki $M, A$, Elliot $P$, Tapanainen $P$, Sovio $U$, Ruokonen A, et al. Adolescent manifestations of metabolic syndrome among children born to women with gestational diabetes in a general-population birth cohort. American Journal of Epidemiology 2009; 169(10): 1209-15. https://doi.org/10.1093/aje/kwp020

[47] Jagiello KP, Chertok IRA. Women's experiences with early breastfeeding after gestational diabetes. Journal of Obstetric, Gynecologic, \& Neonatal Nursing 2015; 44(4): 500-9. https://doi.org/10.1111/1552-6909.12658

[48] Haile ZT, Oza-Frank R, Chertok IRA, Passen N. Association between history of gestational diabetes and exclusive breastfeeding at hospital discharge. Journal of Human Lactation 2016; 32(3): NP36-43. https://doi.org/10.1177/0890334415618936

[49] Riddle SW, Nommsen-Rivers LA. A case control study of diabetes during pregnancy and low milk supply. Breastfeeding Medicine 2016 11(2): 80-5. https://doi.org/10.1089/bfm.2015.0120

[50] Lederman SA, Paxton A. Maternal reporting of prepregnancy weight and birth outcome: consistency and completeness compared with the clinical record. Maternal and Child Health Journal 1998; 2(2): 123-6. https://doi.org/10.1023/A:1022996924094

(C) 2018 Mosli et al.; Licensee Lifescience Global.

This is an open access article licensed under the terms of the Creative Commons Attribution Non-Commercial License (http://creativecommons.org/licenses/by-nc/3.0/) which permits unrestricted, non-commercial use, distribution and reproduction in any medium, provided the work is properly cited. 